\title{
Chromosome Restriction Enzyme Digestion in Domestic Pig (Sus scrofa) Constitutive heterochromatin arrangement
}

\author{
Filomena Adega, Raquel Chaves* and Henrique Guedes-Pinto \\ Department of Genetics and Biotechnology, Centre of Genetics and Biotechnology \\ - CGB University of Trás-os-Montes and Alto Douro - \\ UTAD P-5000-911 Vila Real, Portugal
}

(Received 29 November 2004, accepted 17 February 2005)

\begin{abstract}
The bimodal karyotype of pig appears to contain two types of constitutive heterochromatin, reflecting different satellite DNA families: GC-rich heterochromatin located mainly in the centromeric regions of the biarmed chromosomes, and lessGC-rich heterochromatin in the centromeric regions of the one-armed chromosomes. In order to better discriminate this constitutive heterochromatin, we treated pig chromosome preparations with eight different restriction endonucleases, followed by C-banding. This technique allowed an expedited characterization of the constitutive heterochromatin and demonstrated its great heterogeneity in pig chromosomes. Our work allowed the detection and identification of twenty-two heterochromatin subclasses (twelve centromeric, four interstitial, five telomeric, and the Yq band). Moreover, several cryptic interstitial and telomeric bands were revealed. The work presented here is useful not only for fundamental studies of chromosome banding and constitutive heterochromatin, but also offers a new approach for pig clinical cytogenetics.
\end{abstract}

Key words: C-banding, chromosome rearrangement, constitutive heterochromatin, In situ RE digestion, Sus scrofa

\section{INTRODUCTION}

The bimodal karyotype of pig consists of twelve biarmed autosomes, six acrocentrics, a medium submetacentric X, and a small submetacentric Y (Committee for the Standardized Karyotype of the Domestic Pig 1988). The heterochromatin in pig chromosomes seems to be of two types: GC-rich heterochromatin located mainly in the centromeric regions of the biarmed chromosomes, and less-GC-rich heterochromatin in the centromeric regions of the one-armed chromosomes (Schnedl et al., 1981; Committee for the Standardized Karyotype of the Domestic Pig, 1988).

A substantial proportion of the higher eukaryote genome consists of constitutive heterochromatin $(\mathrm{CH})$. This genomic fraction includes, among other repetitive sequences, satellite DNAs that usually reside in the centromeric regions of chromosomes (Chaves et al., 2000). In swine, two distinct major centromeric satellite DNA families, Mc1 and Ac2, have been described (Jantsch et al., 1990). The Mc1 family is found in the metacentric chromosomes ( 1 to 12 ) and the $\mathrm{X}$ chromosome, whereas the Ac2 family is found in the acrocentric chromosomes

Edited by Yoichi Matsuda

* Corresponding author. E-mail: rchaves@utad.pt
(13 to 18). No satellite DNA repeat has yet been described for the Y chromosome (Rogel-Gaillard et al., 1997a; Janzen et al., 1999). A number of additional metacentric satellite DNA repeats have been isolated from pig genomic DNA (Miller et al., 1993) and from porcine YACs (Rogel-Gaillard et al., 1997b) or cosmid clones containing centromere sequences (Janzen et al., 1999). Another distinct satellite DNA family, Mc2, has been identified from metacentric chromosome 11 (Riquet et al., 1996). The primed in situ (PRINS) labeling technique with primers derived from the Ac1 and Mc1 DNA families has been used to label the centromeres of several subgroups of swine chromosomes, and represents another tool for identifying regions containing repetitive DNA in swine (RogelGaillard et al., 1997a).

The C-banding technique is extremely useful for the identification of constitutive heterochromatin and examination of its size differences. On the other hand, other analytical techniques are necessary to obtain additional information on the nature and origin of the $\mathrm{CH}$. Among these techniques, the use of restriction endonucleases (REs), which cleave DNA at specific sequences, and of base-specific fluorochromes, which delimit chromosome regions rich in different types of DNA bases, have proven to be very useful in improving the understanding of the mechanisms involved in the evolution of $\mathrm{CH}$ in different 
genomes (Pieczarka et al., 1998; for a review see Gosálvez et al., 1997). The use of $\mathrm{RE}$ techniques also has the ability to demonstrate C-heterochromatin heterogeneity (Babu, 1988).

In this study, we treated chromosome preparations of Sus scrofa with eight different restriction endonucleases. The constitutive heterochromatin of individual chromosomes was analyzed with C-banding techniques. The in situ RE-banding was shown to be suitable for analyzing the organization of pig karyotypes. The RE digestion with sequential C-banding technique allowed an expedited characterization of the $\mathrm{CH}$ in terms of its localization, detection of different $\mathrm{CH}$ subclasses, and determination of the $\mathrm{CH}$ molecular composition. The data presented here show that our technique is a useful tool for fundamental studies of chromosome banding and constitutive heterochromatin, and also provides an alternative approach in pig clinical cytogenetics.

\section{MATERIALS AND METHODS}

Chromosome preparations The chromosome preparations were made from short-term lymphocyte cultures of whole blood samples obtained from 15 individuals of Sus scrofa, Suidae.

Briefly, peripheral blood was cultured at $37^{\circ} \mathrm{C}$ using standard protocols (Chaves et al., 2002). Cells were allowed to swell in $75 \mathrm{mM} \mathrm{KCl}$ hypotonic solution at $37^{\circ} \mathrm{C}$ for $20 \mathrm{~min}$, and then fixed by treatment three times with methanol:acetic acid solution (3:1), and left overnight at $-20^{\circ} \mathrm{C}$.

GTD-banding Air-dried slides were aged at $65^{\circ} \mathrm{C}$ for 5 $\mathrm{h}$ or overnight, and then were subjected to standard Gbanding procedures with trypsin (Verma \& Babu, 1995). As the chromosome slides were to be processed by sequential C-banding techniques, they were not stained at this stage. Instead, they were first fixed with paraformaldehyde as described by Chaves et al. (2002). Briefly, dry slides were placed in $1 \times$ PBS solution twice for $5 \mathrm{~min}$ each before fixation in $4 \%$ paraformaldehyde (Sigma) $/ 1 \times$ PBS at room temperature. After fixation for $10 \mathrm{~min}$, slides were dehydrated for 2 min each in 70, 90 and $100 \%$ chilled ethanol and air dried. At this step, slides were stained with DAPI instead of routine Giemsa to achieve better contrast (Chaves et al., 2002). The inversion of the DAPI color in Adobe Photoshop revealed the chromosomes' G-banding pattern (GTD-banding, G-bands by trypsin with DAPI), which was used for their identification. The nomenclature used for the chromosomes of the domestic pig was that of the Committee for the Standardized Karyotype of the Domestic Pig (1988).

In situ RE digestion Air-dried slides were aged at $65^{\circ} \mathrm{C}$ for $6 \mathrm{~h}$, and then were submitted to in situ RE diges- tion. The eight restriction enzymes used (AluI, ApaI, BamHI, DraI, HaeIII, MboI, PstI and RsaI) were diluted in buffers recommended by the manufacturer (Invitrogen, Life Technologies) to final concentrations of $30 \mathrm{U}$ per 100 $\mu \mathrm{l}$. One hundred microliters of each of these solutions were placed on slides and covered with coverslips. The slides were incubated in a moist chamber for $16 \mathrm{~h}$ at $37^{\circ} \mathrm{C}$. Control slides were given the same treatment as described above but were incubated only with buffer. The slides were then washed in distilled water and airdried. As the chromosome slides were to be subjected to sequential C-banding techniques, they were not stained at this stage. Instead, they were first fixed with paraformaldehyde using the technique of Chaves et al. (2002) described above briefly for GTD-banding. Finally, the slides were stained with DAPI (the inversion of the DAPI color revealed the RE-banding). The residual bands obtained after the endonuclease digestion were suitable for chromosome identification. The domestic pig karyotypes were organized following the recommendations of the Committee for the Standardized Karyotype of the Domestic Pig (1988).

CBP-banding sequential to G-banding or RE-banding The C-banding technique was performed sequentially to G-banding or to restriction enzyme banding after destaining the slides. CBP-banding (C-banding by barium hydroxide using propidium iodide) was done using the standard procedure of Sumner (1972) but with propidium iodide as a counterstain. The use of either Giemsa or propidium iodide counterstaining produces similar results to C-band identification. However, there are some technical limitations that must be avoided. For example, the intensity of the bands in $\mathrm{RE}$ treatments seems to be related to the type of counterstain used, e.g., Giemsa or fluorochromes (Gosálvez et al., 1991); therefore, it is not advisable to compare the results obtained using different counterstains.

Briefly, the slides were subjected to routine C-banding using classical treatments whose times were reduced to approximately half: hydrochloric acid $(0.1 \mathrm{M}) 20 \mathrm{~min}$, barium hydroxide (5\% solution) $7 \mathrm{~min}$ and $2 \times \mathrm{SSC}(0.3 \mathrm{~mol} /$ $1 \mathrm{NaCl}, 0.03 \mathrm{~mol} / \mathrm{l}$ sodium citrate) at $60^{\circ} \mathrm{C}$ for only 40 min. The slides were counterstained with $1.5 \mu \mathrm{g} / \mathrm{ml}$ propidium iodide.

Chromosome observation Chromosomes were observed with a Zeiss Axioplan 2 Imaging microscope coupled to an Axiocam digital camera with AxioVision software (version 2.0.5 - Zeiss). Digitized photos were prepared for printing using Adobe Photoshop (version 5.0); contrast and color optimization were performed, and affected all parts of the image equally. 


\section{RESULTS}

We treated chromosome preparations of Sus scrofa with eight different restriction enzymes (RE). The constitutive heterochromatin $(\mathrm{CH})$ of individual chromosomes was then analyzed with sequential C-banding techniques. The residual $\mathrm{RE}$ bands were useful for the identification of chromosomes. The $\mathrm{CH}$ was mainly found in the centromeres of most chromosomes, although some restriction endonucleases, e.g. DraI, showed CH at interstitial locations.

The results obtained using the eight different REs and $\mathrm{REs}+\mathrm{C}$-banding in the pig chromosomes are presented in Fig. 1. The images are representative of at least 35 metaphase preparations observed for each RE analyzed, in no less than five experiments performed at different times. In the left column of Fig. 1, we present control Gbanded and C-banded chromosomes, which are the comparative controls for the analysis of the eight different $\mathrm{RE}$ actions. The G-banding technique was used only for the identification of chromosomes in the control experiment of C-banding without treatment with in situ RE digestion.

In the fifteen individuals analyzed, some heterochromatin polymorphisms of minor significance were detected. These chromosome polymorphisms did not interfere with the heterochromatin patterns presented, and are discussed below.

In situ RE-banding The residual RE bands enable the identification of all chromosomes and are mainly G-like (Fig. 1). The banding patterns demonstrated for each $\mathrm{RE}$ are reproducible, and the preparations can be used in sequential experimental procedures without the loss of chromosome morphology. Overall, the chromosome banding produced with most of the REs has the same or higher band resolution compared to that in the currently available pig karyotype standardization at around 250 band resolution level (Committee for the Standardized Karyotype of the Domestic Pig, 1988).

Restriction endonucleases such as AluI, ApaI and PstI produce clear G-like banding patterns that can be used instead of the routine G-banding. Moreover, the AluIbanding further demonstrated a centromeric C-banding pattern for the acrocentric chromosomes. In several chromosomes, some enzymes also revealed terminal bands that routinely are only produced by R-banding procedures (e.g. telomeric p band in chromosome 3 with $A l u \mathrm{I}$ banding, Fig. 1).

In situ RE digestion and sequential C-banding The C-bands in the control experiment were identified by letters (bands $\mathrm{a}, \underline{\mathrm{b}}$ and $\underline{\mathrm{c}}$ ) according to their order of appearance in each chromosome (Fig. 1). We identified centromeric, interstitial and telomeric C-bands. When we applied REs and sequential C-banding it was possible to verify C-band heterogeneity. As previously described by us (Chaves et al., 2004), this $\mathrm{CH}$ heterogeneity was revealed to be present at two different levels: intra-band $\mathrm{CH}$ variation (in which sub-bands or minor bands are present in a major control C-band) and inter-band $\mathrm{CH}$ variation (in which different bands have distinct subclasses of $\mathrm{CH}$ or a different molecular nature, and so a different molecular composition in their $\mathrm{CH}$ ). In the present work we discuss mainly the inter-band $\mathrm{CH}$ variation.

It is worth mentioning that there is no agreement on the relationship between the loss of DNA by extraction after RE treatment and reduction in staining (Gosálvez et al., 1991). Therefore, in the present work we do not state that a specific chromosome C-band is susceptible to DNA extraction by a particular restriction endonuclease "attack". Instead, we refer to the action of a restriction endonuclease in C-bands related to band staining size. (c.f. Table 1, band + , $r$ or -). Thus, the effects of the eight REs on the chromosomes (Fig. 1) are classified in Table 1 according to Chaves et al. (2004), in which RE+C-banding patterns were compared with the $\mathrm{C}$-banded chromosomes, as presence (+) or absence (-) of specific $\mathrm{RE}+\mathrm{C}-$-bands, and $\mathrm{RE}+\mathrm{C}-$ bands of reduced size ( $\mathrm{r}$ ). Some $\mathrm{RE}+\mathrm{C}$-bands were shown to be larger than in the control C-banding (e.g. telomeric band $\underline{\mathrm{c}}$ of chromosome 1 in $\mathrm{Mbo \textrm {I }}+\mathrm{C}$ ); however, these bands were not discriminated in the classification and were only classified by presence (+). These special cases, where the chromosome bands were larger after the $\mathrm{RE}$ treatments compared with the control C-bands, could be explained by the fact that $\mathrm{RE}$ digestion may increase the staining (in the present work, propidium iodide) capacity in specific chromosome regions (Gosálvez et al., 1997; Nieddu et al., 1999; Chaves et al., 2004).

In this study it was possible to confirm that the eight $\mathrm{REs}+\mathrm{C}$ banding patterns in pig autosomes were different for centromeric, interstitial and telomeric bands. The panel of eight $\mathrm{REs}+\mathrm{C}$ revealed different actions for each interstitial and telomeric band analyzed, and also a different behavior compared to that of the centromeric bands. Exceptions were the telomeric and centromeric bands of chromosome 2 (bands $\underline{a}$ and $\underline{b}$, respectively), which exhibited the same digestion patterns for the entire $\mathrm{REs}+\mathrm{C}$ panel tested. The molecular constitution of these two bands seems to be similar, which could indicate a common origin. The interstitial and telomeric bands of the $\mathrm{X}$ chromosome and the $\mathrm{Y}$ chromosome $\mathrm{CH}$ band also showed very different $\mathrm{CH}$ digestion patterns compared to the autosomes, being suggestive of a different molecular $\mathrm{CH}$ constitution and consequently different $\mathrm{CH}$ classes.

The $\mathrm{RE}+\mathrm{C}$ centromeric bands of autosomes demonstrated different staining patterns when analyzing biarmed and acrocentric chromosomes (Table 1). The $\mathrm{Hae} \mathrm{III}+\mathrm{C}$ digestion patterns were very useful for distinguishing between the centromeric heterochromatin of 


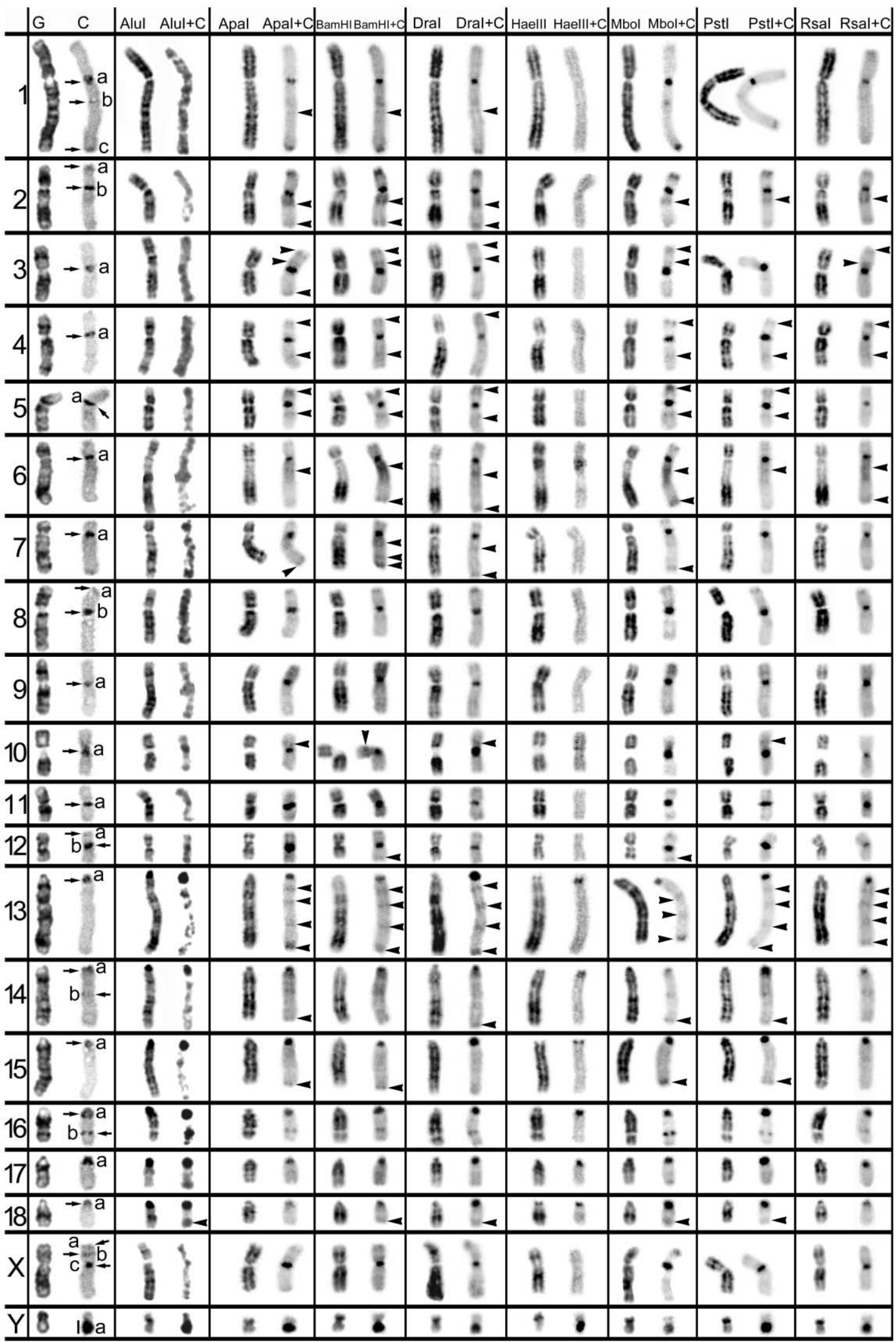

Fig. 1. Control G- and C-banding patterns are shown on the left. The classical C-bands are indicated by arrows and letters of the alphabet ( $a, b$ and c) according to their order of appearance. The other columns show the bands produced by the eight different restriction endonucleases before and after C-banding. Arrowheads indicate cryptic $\mathrm{CH}$ bands. 
Table 1. Tabulation of the bands and their positions produced by the different restriction endonucleases using the chromosomes presented in Fig. 1. (+) presence and (-) absence of specific RE+C-bands, and (r) RE+C-bands of reduced size.

\begin{tabular}{|c|c|c|c|c|c|c|c|c|c|c|}
\hline \multicolumn{11}{|c|}{ Autosome Centromeric RE Bands } \\
\hline $\mathrm{Chr}$ & Bands & Chr Region & $\mathrm{AluI}+\mathrm{C}$ & ApaI+C & $\mathrm{BamHI}+\mathrm{C}$ & DraI+C & $\mathrm{HaeIII+C}$ & $\mathrm{MboI}+\mathrm{C}$ & PstI+C & $\mathrm{RsaI}+\mathrm{C}$ \\
\hline 1 & $\mathrm{a}$ & Cen & - & $\mathrm{r}$ & $\mathrm{r}$ & $\mathrm{r}$ & - & + & $\mathrm{r}$ & $\mathrm{r}$ \\
\hline 2 & $\mathrm{~b}$ & Cen & - & + & + & + & - & + & + & $\mathrm{r}$ \\
\hline 3 & $\mathrm{a}$ & Cen & - & + & + & $\mathrm{r}$ & - & + & + & + \\
\hline 4 & $\mathrm{a}$ & Cen & - & + & + & $\mathrm{r}$ & - & + & + & + \\
\hline 5 & $\mathrm{a}$ & Cen & - & + & $\mathrm{r}$ & + & - & + & + & $\mathrm{r}$ \\
\hline 6 & $a$ & Cen & - & $\mathrm{r}$ & + & + & - & + & + & + \\
\hline 7 & $\mathrm{a}$ & Cen & - & $\mathrm{r}$ & + & + & - & + & + & $\mathrm{r}$ \\
\hline 8 & $\mathrm{~b}$ & Cen & - & + & + & + & - & + & + & $\mathrm{r}$ \\
\hline 9 & $\mathrm{a}$ & Cen & - & + & + & + & - & + & + & + \\
\hline 10 & $\mathrm{a}$ & Cen & $\mathrm{r}$ & + & + & + & - & + & + & $\mathrm{r}$ \\
\hline 11 & $\mathrm{a}$ & Cen & - & + & + & + & - & + & + & + \\
\hline 12 & $\mathrm{~b}$ & Cen & - & + & + & $\mathrm{r}$ & - & + & + & $\mathrm{r}$ \\
\hline 13 & $\mathrm{a}$ & Cen & + & + & + & + & + & + & + & + \\
\hline 14 & $\mathrm{a}$ & Cen & + & + & + & + & + & + & + & + \\
\hline 15 & $\mathrm{a}$ & Cen & + & + & + & + & $\mathrm{r}$ & + & + & + \\
\hline 16 & $\mathrm{a}$ & Cen & + & + & + & + & $\mathrm{r}$ & + & + & + \\
\hline 17 & $\mathrm{a}$ & Cen & + & $\mathrm{r}$ & $\mathrm{r}$ & + & $r$ & + & + & $\mathrm{r}$ \\
\hline 18 & $\mathrm{a}$ & Cen & + & $\mathrm{r}$ & $\mathrm{r}$ & + & $\mathrm{r}$ & + & + & $\mathrm{r}$ \\
\hline \multicolumn{11}{|c|}{ Autosome Interstitial RE Bands } \\
\hline $\mathrm{Chr}$ & Bands & Chr Region & AluI+C & ApaI+C & $\mathrm{BamHI}+\mathrm{C}$ & DraI+C & HaeIII+C & $\mathrm{MboI}+\mathrm{C}$ & PstI+C & $\mathrm{RsaI}+\mathrm{C}$ \\
\hline 1 & $\mathrm{~b}$ & Int & - & - & + & $\mathrm{r}$ & $\mathrm{r}$ & + & $\mathrm{r}$ & - \\
\hline 14 & $\mathrm{~b}$ & Int & - & + & + & - & - & + & + & + \\
\hline 16 & $\mathrm{~b}$ & Int & + & + & + & + & - & + & $\mathrm{r}$ & $\mathrm{r}$ \\
\hline \multicolumn{11}{|c|}{ Autosome Telomeric RE Bands } \\
\hline Chr & Bands & Chr Region & AluI+C & $\mathrm{ApaI}+\mathrm{C}$ & $\mathrm{BamHI}+\mathrm{C}$ & DraI+C & $\mathrm{HaeIII+C}$ & $\mathrm{MboI}+\mathrm{C}$ & PstI+C & $\mathrm{RsaI+C}$ \\
\hline 1 & $\mathrm{c}$ & Tel & - & + & + & + & - & + & + & - \\
\hline 2 & $\mathrm{a}$ & Tel & - & + & + & + & - & + & + & $\mathrm{r}$ \\
\hline 8 & $\mathrm{a}$ & Tel & - & + & + & + & - & $\mathrm{r}$ & + & $\mathrm{r}$ \\
\hline 12 & $\mathrm{a}$ & Tel & - & + & + & + & - & $\mathrm{r}$ & - & - \\
\hline \multicolumn{11}{|c|}{ Sex Chromosome RE Bands } \\
\hline $\mathrm{Chr}$ & Bands & Chr Region & AluI+C & $\mathrm{ApaI}+\mathrm{C}$ & $\mathrm{BamHI}+\mathrm{C}$ & DraI+C & $\mathrm{HaeIII+C}$ & $\mathrm{MboI}+\mathrm{C}$ & PstI+C & $\mathrm{RsaI}+\mathrm{C}$ \\
\hline $\mathrm{X}$ & $\mathrm{c}$ & Cen & - & + & + & $\mathrm{r}$ & - & + & + & + \\
\hline $\mathrm{X}$ & $\mathrm{b}$ & Int & - & - & - & - & - & - & - & - \\
\hline $\mathrm{X}$ & $\mathrm{a}$ & Tel & - & + & + & + & - & + & - & - \\
\hline $\mathrm{Y}$ & $\mathrm{a}$ & $q$ & + & + & + & $\mathrm{r}$ & + & $\mathrm{r}$ & + & + \\
\hline
\end{tabular}

these two chromosome types. In contrast, the $M b o \mathrm{I}+\mathrm{C}-$ bands were similar for both types (biarmed and acrocentric chromosomes) of centromeric heterochromatin. In summary, the centromeric bands of the acrocentric chromosomes demonstrated a different behavior with $A p a \mathrm{I}+\mathrm{C}$, Bam $\mathrm{HI}+\mathrm{C}, \mathrm{Hae} \mathrm{III}+\mathrm{C}$ and $R s a \mathrm{I}+\mathrm{C}$ digestions; the biarmed chromosome centromeric bands showed different digestion patterns for $A l u \mathrm{I}+\mathrm{C}, A p a \mathrm{I}+\mathrm{C}, B a m \mathrm{HI}+\mathrm{C}, \operatorname{Dr} a \mathrm{I}+\mathrm{C}$,
Pst $\mathrm{I}+\mathrm{C}$, and $R s a \mathrm{I}+\mathrm{C}$ among the eight REs tested. Therefore, the autosome centromeric heterochromatin exhibits at least twelve distinct sub-bands.

Fig. 1 and Table 1 reveal that from the twenty-nine Cbands analyzed (nineteen centromeric, four interstitial, five telomeric and the Yq bands) it was possible to discriminate twenty-two subclasses of $\mathrm{CH}$ (twelve centromeric, four interstitial, five telomeric and the Yq bands) 
with this $\mathrm{RE}+\mathrm{C}$ technique. The $\mathrm{RE}+\mathrm{C}$ digestion panel also revealed several cryptic interstitial and telomeric $\mathrm{CH}$ bands (arrowheads in Fig. 1).

\section{DISCUSSION}

In situ RE-banding patterns in pig chromosomes are useful for the organization of karyotypes with similar resolution to that of classical G-banding (Fig. 1). This technique has also the advantage of being reproducible, at least for mammalian (Chaves et al., 2002; 2004) and bivalve (Leitão et al., 2004) chromosomes. REs such as $A l u \mathrm{I}, A p a \mathrm{I}$ and PstI are very useful for producing G-like banding patterns in pig chromosomes.

This report demonstrates that in situ restriction endonuclease digestion with sequential C-banding could be an alternative tool for the study of constitutive heterochromatin heterogeneity in pig chromosomes. This heterogeneity of the molecular composition of $\mathrm{CH}$ is indicative of the presence of different types of repetitive DNA, namely satellite DNA families, in the $\mathrm{CH}$ major blocks (Chaves et al., 2004). The RE digestion with sequential C-banding technique allows the characterization of the $\mathrm{CH}$ (in terms of its chromosomal localization, detection of different $\mathrm{CH}$ subclasses, and revelation of the $\mathrm{CH}$ molecular composition) more accurately than the classical single C-banding, which only localizes the major $\mathrm{CH}$ blocks. As far as we know, this is the first study of $\mathrm{CH}$ heterogeneity using in situ restriction endonuclease digestion (RE-banding) followed by $\mathrm{C}$-banding $(\mathrm{RE}+\mathrm{C}$-banding) in pig chromosomes.

The classical C-banding technique used in the present work detected the major $\mathrm{CH}$ blocks in pig chromosomes. The centromeric heterochromatin blocks detected in all autosomes and the $\mathrm{X}$ chromosome are in agreement with the results of other authors (Lin et al., 1982; Di Meo et al., 1998). However, the use of $\mathrm{RE}+\mathrm{C}$-banding with eight different REs allowed the allocation of these major centromeric $\mathrm{CH}$ blocks into twelve different $\mathrm{CH}$ centromeric sub-classes (Fig. 1 and Table 1). Corresponding bands identified by chromosomal locations exhibit similar reactions among the various pig chromosomes, which is demonstrative of a common origin and phylogenetic proximity (Chaves et al., 2004). Therefore, the autosomal centromeric $\mathrm{CH}$ blocks of chromosomes 2 and 8,3 and 4 , 9 and 11, 13 and 14, 15 and 16, and 17 and 18 all belong to the same $\mathrm{CH}$ subclass.

The centromeric bands of the acrocentric chromosomes demonstrated a different behavior with ApaI+C, Bam HI+C, HaeIII+C and RsaI+C digestions. The centromeric bands of the biarmed chromosomes showed different digestion patterns for $A l u \mathrm{I}+\mathrm{C}, A p a \mathrm{I}+\mathrm{C}, B a m \mathrm{HI}+\mathrm{C}$,

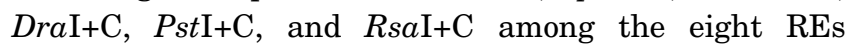
tested. Some of these $\mathrm{RE}+\mathrm{C}$ digestion patterns were very useful for discriminating the centromeric heterochromatin, e.g., $\mathrm{Alu} \mathrm{I}+\mathrm{C}$ and $\mathrm{Hae} \mathrm{III}+\mathrm{C}$ of both biarmed and acrocentric autosomes. In this respect, Table 1 suggests that the pig karyotype with bimodal autosomes has a very different molecular nature with respect to its $\mathrm{CH}$ content. A similar conclusion was achieved by the study of two DNA satellite pig families: the Ac2 family that hybridizes to centromeric heterochromatin of acrocentric chromosomes, and the Mc1 family that hybridizes to centromeric heterochromatin of all biarmed chromosomes (Jantsch et al., 1990; Kalitsis and Choo, 1997; Rogel-Gaillard et al., 1997a). The lack of overlap in the chromosomal location of these two satellite DNA families indicates independent evolution of the satellite DNAs in the two genomes, probably for many millions of years (Jantsch et al., 1990; Kalitsis and Choo, 1997). Moreover, those same authors also stated that the greater homology of the Ac2 satellite DNA in the acrocentric chromosomes might reflect a more recent amplification event in the genome and/or higher rate of sequence homogenization between the acrocentric chromosomes. The same conclusion can be reached from our results: it is possible to observe that on the acrocentric autosome centromeres, four $\mathrm{RE}+\mathrm{C}$ treatments demonstrated a similar effect, while on the biarmed autosome centromeres, only two $\mathrm{RE}+\mathrm{C}$ treatments showed identical effects. This observation is demonstrative of a higher homogenization or, alternatively, a similar molecular composition for the acrocentric centromeric constitutive heterochromatin.

The $\mathrm{RE}+\mathrm{C}$ digestions show that the centromeric $\mathrm{CH}$ band of the $\mathrm{X}$ chromosome belongs to the same $\mathrm{CH}$ subclass as those of chromosomes 3 and 4 . This fact is not surprising since some pig satellite DNA families also hybridize to both the biarmed and $\mathrm{X}$ chromosome centromeres: the Mc1 family hybridizes to all biarmed chromosome centromeres, including the X-chromosome centromere (Jantsch et al., 1990; Rogel-Gaillard et al., 1997a), and the SSCSR1A pig satellite family hybridizes mainly to centromeres of the biarmed chromosomes 3 and $\mathrm{X}$, and less intensely to chromosomes 4, 6 and 7 (Miller et al., 1993; Rogel-Gaillard et al., 1997a).

By observation of the $\mathrm{RE}+\mathrm{C}$-banding in the pig karyotype it is possible to discriminate twenty-nine C-bands, which are divided into four categories based on position: centromeric, interstitial, telomeric, and the Yq band, and to discriminate twenty-two subclasses of $\mathrm{CH}$ (twelve centromeric, four interstitial, five telomeric and the Yq band) (Fig. 1 and Table 1). The large $\mathrm{CH}$ heterogeneity found in pig chromosomes leads to the assumption that this heterochromatin could be ancient, or a consequence of rapid turnover of repetitive DNA families. The large number of pig $\mathrm{CH}$ subclasses identified in this paper deserve further investigations at the molecular level, namely the isolation and characterization of greater numbers of repetitive DNA families. This would certainly allow the isolation of repetitive sequences specific for each pig chromosome, as has already been done for the human repeti- 
tive DNA families.

Finally, the RE-C digestion panel also revealed several cryptic interstitial and telomeric $\mathrm{CH}$ bands. All these cryptic $\mathrm{CH}$ bands were assigned in $\mathrm{G}$ light-stained regions. One of the obvious applications is for the detection and identification of these specific bands in pig clinical cytogenetics. Several structural chromosome rearrangements are known in pig and some of them are responsible for important decreases in the reproductive performance of carrier animals or their mates, which justifies the major control programs carried out in various countries (Ducos et al., 2002). The continuous improvement of chromosome banding techniques has made possible the identification and characterization of new chromosome rearrangements (Popescu et al., 1998). However, breakpoint regions of chromosome rearrangements occurring in the light-stained G-bands or in the band's interface are sometimes hard to define and necessitate alternative banding procedures, e.g., R-banding, or fluorescent in situ hybridization analysis (ISCN 1995). Furthermore, $\mathrm{CH}$ regions are thought to be "hotspots" for structural chromosome rearrangements (Yunis and Yasmineh, 1971; Peacock et al., 1982; John, 1988; Chaves et al., 2004). We compared thirteen reciprocal translocations described by Ducos et al. (1998; 2002) with the chromosome regions of the cryptic $\mathrm{CH}$ bands described in the present paper, and found that some of them are located in the breakpoints defined by those authors, namely $2 q 13$, 4q21, 7q24, 13q41 (Fig. 1). Besides, the thirteen reciprocal translocations involve a total of twenty-six breakpoints, of which twenty-two lay in $G$ light-stained regions. Obviously, not all negative G-bands will be shown to have $\mathrm{RE}+\mathrm{C}$ bands, but surely if we increase the $\mathrm{RE}$ panel tested, more of these cryptic bands could be described and help to identify these pig chromosome rearrangements.

This technique described here is not only useful for fundamental banding and constitutive heterochromatin studies, but also provides a new approach for pig clinical cytogenetics. Further investigations should be carried out at the molecular level, such as cloning and analysis of porcine repetitive sequences, in order to achieve further insights into the heterochromatin composition of the pig.

This work was partially supported by a $\mathrm{PhD}$ grant, $\mathrm{SFRH} / \mathrm{BD} /$ $3280 / 2000$, of the Science and Technology Foundation (FCT) of Portugal.

\section{REFERENCES}

Babu, A. (1988) Heterogeneity of heterochromatin of human chromosomes as demonstrated by restriction endonuclease treatment. In: Heterochromatin: Molecular and Structural Aspects (ed.: R. S. Verma), pp. 250-275 in, CambridgeUniversity Press, United States of America.
Chaves, R., Adega, F., Santos, S., Heslop-Harrison, J. S., and Guedes-Pinto, H. (2002) In situ hybridization and chromosome banding in mammalian species. Cytogenet. Genome Res. 96, 113-116.

Chaves R, Guedes-Pinto H, Heslop-Harrison J. S., Schwarzacher T. (2000) The species and chromosomal distribution of the centromeric a-satellite I sequence from sheep in the tribe Caprini and other Bovidae. Cytogenet. Cell Genet. 91, 6266.

Chaves, R., Santos, S., and Guedes-Pinto, H. (2004) Comparative analysis (Hippotragini versus Caprini, Bovidae) of $\mathrm{X}$ chromosome's constitutive heterochromatin by in situ restriction endonuclease digestion: X-chromosome constitutive heterochromatin evolution. Genetica 121(3), 315-325.

Committee for the Standardized Karyotype of the Domestic Pig (1988) Standard karyotype of the domestic pig. Hereditas 109, 151-157.

Di Meo, G. P., Perucatti, A., Ferrara, L., Palazzo, M., Matassino, D., and Iannuzzi, L. (1998) Constitutive heterochromatin distribution in pig (Sus scrofa) chromosomes. Caryologia, 51(1), 65-72.

Ducos, A., Pinton, A., Berland, H. M., Séguéla, A., Blanc, M. F., Darre, A., and Darré, R. (1998) Five new cases of reciprocal translocation in the domestic pig. Hereditas 128, 221-229.

Ducos, A., Pinton, A., Yerle, M., Séguéla, A., Berland, H. M., Brun-Baronnat, C., Bonnet, N., and Darré, R. (2002) Cytogenetic and molecular characterization of eight new reciprocal translocations in the pig. Estimation of their incidence in French populations. Genet Sel Evol 34, 389-406.

Gosálvez J, Mezzanotte R., López-Fernández C., Del Castillo P., Stockert J. C., Goyannes V, Sumner A. T. (1991) Selective digestion of mouse chromosomes with restriction endonucleases. II. X-ray microanalysis of Hae III-treated chromosomes. Cytogenet. Cell Genet. 56, 82-86.

Gosálvez, J., López-Fernández, C., Goyanes, V., and Mezzanotte, R. (1997) Chromosome differentiation using nucleases: an overview. In: Chromosomes Today (eds.: Henriques-Gil, J. S. Parker, and M. J. Puertas), vol. 12 N. Chapman \& Hall, London.

ISCN 1995 An International System for Human Cytogenetic Nomenclature (ed.: F. Mitelman). S. Karger, Basel.

Jantsch, M., Hamilton, B., Mayr, B., and Schweizer, D. (1990) Meiotic chromosome behavior reflects levels of sequence divergence in Sus scrofa domestica satellite DNA. Chromosoma 99, 330-335.

Janzen, M. A., Buoen, L. B., Zhao, F., and Louis, C. F. (1999) Characterization of a swine chromosome-specific centromeric higher-order repeat. Mamm. Genome 10, 579-584.

John, B. (1988) The biology of heterochromatin, in Heterochromatin: molecular and structural aspects. (ed.: R. S. Verma). Cambridge University Press, United States of America.

Kalitsis, P., and Choo, K. H. A. (1997) Centromere DNA of higher eukaryotes. In: The centromere (ed.: K. H. A. Choo). Oxford University Press Inc., New York.

Leitão, A., Chaves, R., Santos, S., Guedes-Pinto, H., and Boudry, P. (2004) Restriction enzyme digestion chromosome banding in Crassostrea and Ostrea species: comparative karyological analysis within Ostreidae. Genome 47(5), 781-788.

Lin, C. C., Joyce, E., Biederman, B. M., and Gerhart, S. (1982) The constitutive heterochromatin of porcine chromosomes. J. Hered. 73, 231-233.

Miller, J. R., Hindkjaer, J., and Thomsen, P. D. (1993) A chromosomal basis for the differential organization of a porcine centromere-specific repeat. Cytogenet. Cell Genet. 62(1), $37-41$. 
Nieddu, M., Rossino, R., Pichiri, G., Rocchi, M., Setzu, M. D., and Mezzanotte, R. (1999) The efficiency of in-situ hybridization on human chromosomes with alphoid DNAs is enhanced by previous digestion with AluI and TaqI. Chrom. Res. 7, 593-602.

Peacock, W. J., Dennis, E. S., and Gerlach, W. L. (1982) DNA sequences and speciation. In: Mechanisms of speciation (eds.: C. Barigozzi, and Alan R. Liss). New York.

Pieczarka, J. C., Nagamachi, C. Y., Muniz, J. A., Barros, R. M. and Mattevi, M. S. (1998) Analysis of constitutive heterochromatin of Aotus (Cebidae, Primates) by restriction enzyme and fluorochrome bands. Chromosome Res. 6, 7783.

Popescu, C. P., Hyes, H., and Dutrillaux, B. (1998) Techiques de cytogéneétique animale. INRA Éditions, Paris.

Rogel-Gaillard, C., Hayes, H., Coullin, P., Chardon, P., and Vaiman, M. (1997a) Swine centromeric DNA repeats revealed by primed in situ (PRINS) labeling. Cytogenet. Cell Genet. 79, 79-84.
Rogel-Gaillard, C., Borgeaux, N., Save, J. C., Renard, C., Coullin, P., Pinton, P., Yerle, M., Vaiman, M., and Chardon, P. (1997b) Construction of a swine YAC library allowing an efficient recovery of unique and centromeric repeated sequences. Mamm. Genome 8, 186-192.

Riquet, J., Mulsant, P., Yerle, M., Cristobal-Gaudy, M. S., and Le Tissier, P. et al. (1996) Sequence analysis and genetic mapping of porcine chromosome 11 centromeric S0048 marker. Cytogenet. Cell Genet. 74, 127-132.

Sumner, A. T. (1972) A simple technique for demonstrating centromeric heterochromatin. Exp. Cell Res. 75, 304-306.

Schnedl, W., Abraham, R., Förster, M., and Schweizer, D. (1981) Differential fluorescent staining of porcine heterochromatin by chromomycin A3/distamycin A/DAPI and D287/170. Cytogenet. Cell Genet. 31, 249-253.

Verma, R. S., and Babu, A. (1995) Human Chromosomes: Principles and Techniques. McGraw Hill, New York.

Yunis, J. J., and Yasmineh, W. G. (1971) Heterochromatin, satellite DNA and cell function. Science 174, 1200-1209. 